\title{
Justicia como redistribución, reconocimiento y representación: Las reconciliaciones de Nancy Fraser
}

\author{
Clara IGLESIAS \\ Facultad de Filosofía \\ Universidad Complutense de Madrid \\ idut.cir@gmail.com
}

Recibido: 28.05 .2012

Aceptado: 1.10.2012

\section{RESUMEN}

Si nos preguntamos por el desarrollo de la Teoría Crítica y sus marcos conceptuales, es imprescindible tener en cuenta el pensamiento de Nancy Fraser. Con el presente artículo se pretende desglosar el entramado conceptual del que se vale Fraser, tomando para ello principalmente dos de sus obras: ¿Redistribución o reconocimiento? y Escalas de justicia. Con ello el artículo se centra en la consideración de conceptos clave para la elaboración de una teoría crítica capaz de integrar las reivindicaciones actuales presentes en los movimientos sociales, y con ello la puesta de manifiesto de la injusticia y su posible reparación, sin perder de vista en ningún momento el correlato social fáctico de la teoría.

Palabras clave: Redistribución, reconocimiento, representación, actor social, esfera pública, justicia.

\section{Justice as Redistribution, Recognition and Representation: Nancy Fraser's Reconciliations}

\begin{abstract}
If we are asking about the development of the critical Theory, and also about the conceptual (and actual) frames to our society, it is always necessary to keep in mind Nancy Fraser's Theory. This paper is a description but also an explanation of Fraser's thinking, taking two of her main books to describe its' development: Redistribution or recognition? and Scales of justice. Therefore, this essay is focused on important concepts to (re)elaborate a critical Theory capable of the understanding of the actual claims and demands of social movements, as well as remarking the injustice and her possible reparation, without missing the factual connection between her the theory and our Society.
\end{abstract}

Key words: redistribution, recognition, representation, social actor,public sphere, justice.

\section{PARA UNA PRIMERA APROXIMACIÓN.}

En los últimos años podemos contemplar la aparente pérdida de interés por las cuestiones relacionadas con los movimientos sociales, así como con la política en general: solemos hablar de un estancamiento de la crítica social, de una falta 
manifiesta de actividad por parte de movimientos como puede ser el activismo feminista... Podría parecer que esta falta de interés se extiende también al campo de la filosofía política, social y del feminismo filosófico, pero, aunque hay excepciones, no parece ser el caso. Con este artículo se pretende apelar a la necesidad de revisión de dicho problema, tomando como ejemplo la obra de Nancy Fraser.

Es necesario mencionar, al menos de forma breve, las implicaciones de Fraser en el ámbito del feminismo filosófico. Cómo trataré de mostrar, la principal preocupación de Fraser a lo largo de su obra es el hecho de poner de manifiesto las injusticias sociales, y en particular reivindicar las luchas sociales como puede ser el movimiento feminista. Es importante notar cómo Fraser es capaz de conciliar así su pretensión general de desenmascarar los mecanismos que generan injusticia, y buscar las posibles soluciones o alternativas a los mismos, con sus reivindicaciones concretas dentro de los movimientos sociales, tomándolos siempre como ejemplos polémicos, como ocurre con el feminismo. Ahora bien, también es cierto que, en su obra tomada como conjunto, la teoría feminista es siempre uno de sus puntos centrales. Y como veremos que intenta hacer con la teoría crítica, el planteamiento de Fraser sigue una perenne línea orientada a la pluralidad, por lo que se trata siempre de un ejercicio de crítica e integración, es lo que ella misma ha llegado a denominar como un cierto perspectivismo.

Aún así no pretendemos defender aquí que Fraser no realice nada más allá de un titánico acto de compilación, su visión crítica es admirable y como ejemplo, en el caso concreto del papel de la teoría feminista en las descripciones actuales de nuestra sociedad, tenemos el artículo ¿Qué tiene de crítica la teoría crítica? Habermas y la cuestión del género donde expone la distinción entre la definición marxista y la habermasiana de lo que se considera Teoría Crítica. Fraser critica la concepción habermasiana de una teoría crítica debido a que parece excluir al movimiento feminista, ya que:

"[...] uno de los criterios de valoración de una teoría crítica una vez hubiera sido sometida a todas las pruebas habituales de adecuación empírica sería: ¿con qué idoneidad teoriza la situación y perspectivas del movimiento feminista? ¿En qué medida sirve para la autoclarificación de las luchas y anhelos de las mujeres contemporáneas?" (Fraser, 1990: 49-50).

El problema que plantea Fraser es que Habermas no parece tener en cuenta, como muchos otros, el problema del género como parte de su estudio de los marcos (o en su terminología sistemas y subsistemas) sociales, y por ello no sería la suya una teoría verdaderamente crítica. Este punto resulta además muy interesante para aclarar la idea de Fraser de lo que debería significar la teoría crítica. Y también para ilustrar la crítica a la política desde el feminismo, ya que es también por su gran capacidad crítica por lo que interesa este movimiento especialmente. 


\title{
2. REDISTRIBUCIÓN Y RECONOCIMIENTO. DIÁLOGO CON AXEL HONNETH
}

En su obra ¿Redistribución o reconocimiento? escrita junto con el filósofo alemán Axel Honneth, podemos apreciar el carácter 'reconciliador' típico de Fraser. Así, tendríamos por un lado la postura "monista" (según Fraser) de Honneth, que pretende subsumir el problema de la distribución dentro del campo del reconocimiento, mientras que la postura de la propia Fraser se vería como "perspectivista" en el sentido de que abre el margen de posibilidades al no reducir ninguno de ellos al otro, su teoría sería por tanto bidimensional. La peculiar estructura de esta obra nos permite reconocer más claramente que motivos llevan a Fraser a no admitir una reducción para ninguno de los dos campos. Lo que se nos está planteando constantemente es la ardua tarea de diseñar una teoría de la justicia, pero sin perder de vista una dimensión crítica en la misma. No podemos tratar de solventar problemas de injusticia sin antes ser capaces de distinguir cuál de los dos polos predomina en ellas, esto es, si son injusticias derivadas de un reconocimiento fallido o erróneo o de una mala distribución. Lo no quiere decir que en algunos casos no resulte interesante enfocarlo desde ambos puntos de vista.

Necesitamos una nueva perspectiva para enfrentarnos a los problemas actuales de la justicia social. Y tal vez sea uno de nuestros problemas precisamente que no se suele contar con una dimensión crítica al tratar ambos campos por separado. Pero también, como ella misma señala:

\begin{abstract}
"Reconocimiento se ha convertido en una palabra clave de nuestro tempo. Esta idea, una venerable categoría de la filosofía hegeliana, resucitada no hace mucho por los teóricos políticos, está resultando fundamental en los trabajos para conceptualizar los debates actuales acerca de la identidad y la diferencia. [...] Si la relevancia del reconocimiento es, en la actualidad, indiscutible, su relación con la 'redistribución' sigue a falta de un tratamiento teórico suficiente" (Fraser, 2006: 13).
\end{abstract}

Así vemos la falta de una teoría 'equilibrada' capaz de resolver ambos tipos de injusticia.

Con esta primera aproximación critica Fraser además cómo se suele dar una mayor importancia teórica al reconocimiento, lo que sería uno de los motivos de que se considere, generalmente, la distribución o redistribución como un apéndice del mismo, de forma que si éste es válido garantizará una justa y correcta distribución. Aunque con matices, podríamos decir que ésta sería la postura de Honneth, para quién no habría necesidad de duplicar los componentes, se trata de una relación de subordinación que excluye la duplicidad, el concepto de reconocimiento bastaría para subsumir todas las injusticias sociales. Pero para nuestra autora por mucho que se dé 
dicha relación de subordinación en los casos menos problemáticos, no por ello dejan de ser dos aspectos diferenciados.

Es cierto que la integración de redistribución y reconocimiento parece suponer una serie de problemas en el marco de la filosofía moral, pero esto puede deberse a la errónea y común caracterización del reconocimiento como cuestión de realización personal. Ya que esta identificación errónea nos conduciría a nuevos problemas: ¿cómo diferenciamos si las pretensiones de reconocimiento son justificadas o no?, ¿exige la justicia el reconocimiento de lo característico de un individuo o grupo o basta con el reconocimiento de nuestra humanidad? ... La solución que nos propone Fraser aquí es el plantear el problema del reconocimiento dentro del modelo de estatus, como una cuestión de justicia, evitando la psicologización. Así se implicaría también una concepción bidimensional de la justicia que permitiría una justificación de las pretensiones de reconocimiento.

En su propuesta se impone la paridad participativa como norma de justificación, siempre y cuando sea aplicada discursivamente por medio del procedimiento de debate democrático público y no: "monológicamente a modo de un proceso de decisión.” (Fraser, 2006: 47) Además el enfoque dialógico permite el dinamismo histórico. Lo que trata de mostrar Fraser aquí es, además, que las sociedades han de entenderse como campos complejos que engloban (como mínimo) dos modalidades: económica y cultural. Así ni culturalismo ni economicismo pueden definir nuestra sociedad completamente.

Ahora bien, ¿qué clase de teoría podría asumir la compleja tarea de describir nuestra sociedad explicando incluso el problema de la relación de subordinación de estatus con la subordinación de clase social, del reconocimiento erróneo con la mala distribución?

“¿Y qué clase de teoría puede hacer esto sin reforzar la disociación actual de la política de reconocimiento de la política de redistribución? [...] Llamo a este enfoque teoría "dualismo perspectivista". Aquí la redistribución y el reconocimiento no corresponden a dos dominios sociales esenciales: economía y cultura. En cambio, constituyen dos perspectivas analíticas que pueden asumirse en relación con cualquier dominio. Estas perspectivas pueden despegarse en sentido crítico, más aún, contra la moda ideológica" (Fraser, 2006: 61-64).

A partir de este punto la discusión de Fraser se centra en la búsqueda de un enfoque integrado que pueda reparar a la vez el reconocimiento erróneo y la mala distribución. Se proponen dos opciones: reparación transversal y conciencia de los límites. La reparación transversal consistiría en: 
"[...] utilizar medidas asociadas con un dimensión de la justicia para remediar desigualdades asociadas con la otra, es decir, utilizar medidas distributivas para reparar el reconocimiento erróneo y medidas de reconocimiento para reparar la mala distribución. La reparación transversal explota la imbricación de estatus y clase social con el fin de mitigar ambas formas de subordinación al mismo tiempo" (Fraser, 2006: 80).

El problema que nos plantea esta forma de reparación es que no podría usarse de manera sistemática, generalizada. La conciencia de los límites, como ya su propio nombre indica no será otra cosa que: "la conciencia del impacto de diversas reformas sobre los límites del grupo” (Fraser, 2006: 82) El problema que se nos plantea a continuación será un punto crucial en su obra Escalas de justicia: el problema del marco.

Queda con esto pendiente la cuestión de encontrar un esquema programático capaz de integrar con éxito redistribución y reconocimiento, y esto queda así precisamente porque para Fraser "sólo si buscamos enfoques integradores que unan redistribución y reconocimiento podremos satisfacer los requisitos de una justicia para todos." (Fraser, 2006: 88) Así hemos llegado ya a encontrar al menos la dirección en la que debemos orientar nuestra teoría, una reconciliación de redistribución y reconocimiento como garante de justicia.

Fraser defiende su propio enfoque además por su capacidad de mantener una tensión empírico-crítica, de hecho, critica el enfoque monista de Honneth por no ser capaz de solventar los siguientes puntos: punto de referencia empírico, lugar de la cultura y principios normativos de la teoría crítica. Todo el debate se encuentra en el tercer capítulo (Fraser, 2006) como réplica a la crítica de Honneth.

Otro de los problemas que se pone de manifiesto en teorías como la de Honneth es que entiende la o las sociedades sólo en términos de relaciones de reconocimiento, que puede ser mirado como subsumiendo todos los planos sociales, y por ello quedan estancadas en un problema de "identidad personal intacta", que se iría dividiendo en sub-ámbitos: seguridad en sí mismo, respeto a uno mismo, autoestima; para paliar así su falta de perspectiva. Así, el problema central de la teoría "monista" sería su intento de reducción, de eliminación de un segundo eje categorial que Fraser ha mostrado necesario. Tendríamos un solo eje, "el sólo reconocimiento basta para recoger todos los déficits normativos de la sociedad contemporánea, todos los procesos que los generan y todos los retos políticos a los que se enfrentan quienes buscan un cambio emancipador." (Fraser, 2006: 150) Por tanto lo único necesario para la teoría crítica sería dar una explicación claramente "diferenciada" de la noción de reconocimiento, pero manteniéndolo como eje único. Con esto no hace más que mostrar de nuevo, según Fraser, la necesidad de ampliar la noción de reconocimiento, lo que se resolvería con la reconciliación de redistribución y reconocimiento. 


\section{LA DIMENSIÓN DE LA JUSTICIA. PARIDAD DE PARTICIPACIÓN Y EL PROBLEMA DE LA REPRESENTACIÓN}

Un punto que tenemos que tener siempre presente es la continuidad que presentan estas dos obras, ya que Escalas de justicia parece arrancar en el punto exacto en el que se queda ¿Redistribución o reconocimiento?, es decir retoma el punto polémico de la justicia y la paridad de participación que la primera deja como proyecto. Ahora pretende Fraser ocuparse de configurar una teoría de o sobre la justicia capaz de conciliar redistribución y reconocimiento, y para ello otorga un papel esencial a un tercer polo que ya se venía perfilando como posible en la primera obra. Se ve claramente como se da el salto del "dualismo perspectivista" predominante en ¿Redistribución o reconocimiento? a una tríada de conceptos clave, ya que aunque en la obra citada perfila una tercera dimensión (como solución incluso: paridad de participación), no termina de dejar claro el papel de la misma en el conjunto de la teoría.

Como hemos visto ya, uno de los conceptos polémicos del que Nancy Fraser se ocupa ampliamente es el de la justicia. Dentro de su obra Escalas de justicia se proponen, en el primer capítulo, dos métodos para acercarse a este concepto: el mapa y la balanza. También se aborda la diferencia entre una política del reconocimiento y un modelo de redistribución. El análisis de Nancy Fraser se centra en los obstáculos de la justicia social y política y ha constituido un avance teórico frente a los dilemas de la práctica social. En la obra ya citada, también se presentan las tres dimensiones de su teoría de la justicia: la redistribución en la esfera económica, el reconocimiento en el ámbito socio-cultural y la representación en lo político. Así se plantea el problema de un cambio profundo en la gramática en las reivindicaciones políticas actuales. Este cambio parece tener consecuencias sobre un nuevo orden mundial e implicaría una forma diferente de encarar la "justicia doméstica", es decir se plantea el problema del marco, y de cómo se decide quién entra a formar parte de una sociedad concreta, qué es lo 'doméstico', etc. En este contexto, las reivindicaciones de justicia aparecen como un reto nuevo para el uso de la clave "política del enmarque".

El problema que Fraser nos está planteando es claramente complejo: ¿cómo delimitamos la injusticia? ¿Cómo se decide quién o qué puede ser miembro de una sociedad y quién tenga, por tanto, que hacerse cargo de dicha injusticia? El problema de la globalización se toma aquí como transgrediendo el "marco westfalianokeynesiano", en el sentido de que antes las disputas sobre justicia social presuponían dicho marco y así quedaban delimitadas dentro de los Estados territoriales modernos. El problema ahora va más allá, antes no había necesidad de discutir sobre el 'quién', estaba claro que hablábamos de conciudadanos, y que la unidad apropiada era el Estado moderno, lo que preocupaba era el 'qué' ("que se debían los ciudadanos unos a otros" (Fraser, 2008: 33-34)). El problema ahora es que nos enfrentamos a una 
producción transnacional, y así los "movimientos que luchan por el reconocimiento miran cada vez más por encima de los Estados territoriales." (Fraser, 2008: 36)

Lo que se trata de mantener ahora es una tercera dimensión de la justicia: lo político. Ya que este ámbito remite a la naturaleza de la jurisdicción del Estado y a las reglas de decisión. Además, para Fraser, la paridad de representación es vista como el significado más general de justicia, así nos trata de explicar la especificidad de lo político. Fraser plantea dos tipos o niveles de injusticias políticas: la representación fallida político-ordinaria y el des-enmarque. Lo que se nos muestra con esta distinción es que, en la medida en que siempre necesitamos asumir un marco a la hora de llevar a cabo una reivindicación de justicia determinada, siempre estaríamos presuponiendo ya una cierta noción de representación. Así nos muestra el concepto del marco y la noción de representación como formando parte, implícita o explícitamente de cualquier reivindicación, de manera que la dimensión política sería ya parte de la gramática de la justicia, esto es, no hay redistribución ni reconocimiento sin representación.

Razonando así con Fraser, llegamos al problema que ya se venía formulando: con la pérdida del marco "westfaliano-keynesiano" cómo podremos desarrollar una teoría de la justicia si hemos indicado ya que el marco es precisamente un fundamento de la misma. Fraser explica varias teorías con las que se ha tratado de responder a ésta cuestión, y termina por quedarse con el concepto ya expuesto, esto es, la paridad participativa, ya que esta norma:

“[...] Satisface la interpretación de la justicia presentada aquí. [...] Al definir los conceptos del des-enmarque y de representación fallida metapolítica, desvela las profundas injusticias omitidas por las teorías estándar. Centrada no sólo en el 'qué' de la justicia, sino también en el 'quién' y el 'cómo', nos capacita para comprender la cuestión del marco como cuestión central de la justicia en un mundo en globalización" (Fraser, 2008: 64).

Ya centrados en los problemas clave, podemos plantearnos cómo se desarrolla la discusión en el ámbito de la filosofía política. Aquí observamos que hay también un cambio sustancial dentro del igualitarismo, se pasa de la pregunta por el 'qué' (“¿igualdad de qué?” (Fraser, 2008: 68)) a preguntarse también por el 'quién', lo que indica "la superación del primero de los dos dogmas tácitos del igualitarismo: el supuesto tácito del quién nacional con total ausencia del debate que debiera hacerse." (Fraser, 2008: 70) Así llegamos a la conclusión de que cada filósofo decidirá la cuestión del 'quién', según entienda la superación del marco y su cambio de gramática, esto es, según considere cuál es el principal factor que determina las oportunidades vitales de los sujetos en la coyuntura actual. 
Ahora bien, habíamos planteado un tercer polo para esta cuestión, el cómo', para el que no parece encontrarse aún ningún procedimiento claro, así afirma Fraser que los que se ocupan ahora de la justicia deberían tratar de profundizar en este aspecto. Ella nos muestra el "enfoque de ciencia social normal", pero ensayando una alternativa al mismo el "enfoque crítico-democrático". Este segundo enfoque superaría al primero, ya que es capaz de combinar dos ideas fundamentales: "por una parte, una concepción influida por la teoría crítica de relación entre conocimiento social y reflexión normativa; por otra, un interés político-democrático por una confrontación pública imparcial." (Fraser, 2008: 88) Con esta definición se mantiene el interés por un proceso discursivo público ya apuntado en su obra ¿Redistribución o reconocimiento? y el planteamiento de la necesidad de crear un nuevo marco, que no será un mero marco global que lo abarque todo sino más bien un conjunto de marcos múltiples, funcionalmente definidos y que correspondan a los 'quiénes' que debaten y son juzgados.

Pero no podemos dejarlo ahí, aún nos falta discernir qué clase de reivindicaciones de justicia se consideran inteligibles, y qué supuestos subyacen a las ya aceptadas como tales. El problema es ahora, que si delimitamos de antemano qué reivindicaciones son válidas o adecuadas y que ámbitos del discurso avanzan, así como en qué espacio han de ser realizadas podemos toparnos con una injusticia subyacente al propio sistema, ya que no se habría examinado éste suficientemente. Así debemos cuestionar también si un concepto de justicia "monista" (normal) nos sirve o no. Si seguimos a Fraser, está claro que no podemos hablar sino de tres visiones distintas del 'qué' de la justicia, que corresponderían a tres formas diferentes de injusticia no subsumibles o reductibles las unas a las otras. Ya que "es mejor ver la justicia como un concepto multidimensional que comprende las tres dimensiones de redistribución, reconocimiento y representación." (Fraser, 2008: 114-115) El problema ahora es que nos enfrentamos a una "justicia anormal", por ello al referirnos al 'quién' necesitamos tener en cuenta sus dos aspectos, positivo y negativo, así tendremos cuestiones des-enmarcadas, esto es, injusticias de des-enmarque, por lo que necesitamos un aspecto reflexivo de la justicia. Este punto resulta bastante complejo, porque aún admitiendo la teoría de Fraser quedan muchas cuestiones por desarrollar.

Según Fraser no bastaría con el principio del discurso habermasiano, necesitamos una nueva noción de esfera pública que se soporte en "el principio de todos los sujetos" (Fraser, 2008: 179) reinterpretando así el sentido de la exigencia de inclusividad, esto es, es necesario volver a pensar en los fundamentos de las teorías referentes a la legitimidad y a la eficacia de la opinión pública. Para que pueda la teoría de la esfera pública mantenerse fiel en su colaboración con las reivindicaciones y luchas por la emancipación. 
Otro de los puntos fuertes de la teoría de Fraser es, como ella misma indica, que su teoría tridimensional de la justicia o política tridimensional, ofrece una gran oportunidad a lo que podemos denominar como tercera fase de la lucha feminista. Para con ello poder responder a la gran cuestión política actual: “¿cómo podemos integrar las reivindicaciones de redistribución, reconocimiento y representación para desafiar el amplio abanico de injusticias de género en un mundo en globalización?" (Fraser, 2008: 208).

\section{PÚBLICO VERSUS PRIVADO. CÓMO ENTENDER LA ESFERA PÚBLICA}

Un apunte más, vendría a colación a través de la idea de esfera pública. Está claro que la división habermasiana con el famoso 'Lebenswelt' o "mundo de la vida" no satisface por completo las necesidades que plantea la teoría de Fraser, así como que la división arendtiana tampoco, a pesar de que se mantenga la fuerza de su diagnóstico de la dinámica del desastre. Parece por tanto que ambos conceptos, esfera pública y marco, responden a problemas similares, los cuáles seguramente sean tematizados más ampliamente en la obra en desarrollo de Fraser. Pero cuya teorización actual puede resultar un tanto difusa. Así, en los apartados siguientes, trataré de hacer un breve apunte a dos críticas siempre presentes, al menos de fondo, en la concepción que Fraser maneja de esfera pública. Estas no son otras que las críticas a las diferenciaciones arendtiana y habermasiana de público y privado.

\subsection{FRENTE A HABERMAS}

En cuanto a Habermas, y retomando el breve apunte de la introducción, nos referiremos primero a la crítica de Fraser desde la no consideración del subtexto de género por parte de Habermas, ya que es parte de la crítica de Fraser a la esfera pública habermasiana. Lo que no se nos puede escapar es: "que el punto esencial del argumento de Fraser no es que Habermas olvide las formas de subordinación, sino la distinción categorial con que éste las aborda" (Castillo, 2005: 77).

Fraser critica principalmente el hecho de que nos encontramos ante otra teoría más de la separación entre lo público y lo privado. La importancia de esta acusación reside en el hecho de que la filosofía feminista ha considerado estas teorías como base de la subordinación de las mujeres en la sociedad moderna. De manera que si no se introducen correcciones en la teoría de Habermas, esta quedaría como androcéntrica e ideológica en algunos de sus puntos clave. Es cierto que Fraser le concede que la categorización que lleva a cabo en su Teoría de la acción comunicativa es más compleja de lo habitual en otros autores, pero su problema, y Fraser insiste en ello, es no haber tematizado suficientemente el subtexto de género. Esto es, que no ha 
aclarado las marcas de género que poseen los roles que vinculan una esfera con otra, como por ejemplo:

"Si tomamos el rol del trabajador que vincula la economía (oficial) privada con la familia privada en las sociedades capitalistas, descubrimos que es un rol masculino. Los vínculos que parecen existir entre familia y la economía oficial afectan tanto a lo que se refiere a la identidad de género como al dinero. La idea del varón proveedor de alimentos es central en este tipo de economía" (Oliva, 2009:202).

Mientras que la mujer queda relegada "a puestos feminizados y sexualizados, siempre secundarios con lo que se confirma el subtexto masculino del rol de trabajador." (Oliva, 2009:202) Es claro que esta exclusión reduce enormemente el carácter crítico de la teoría habermasiana al no ser capaz de mostrar relaciones que podemos ver en términos de relaciones de poder que subyacen, casi como pequeñas relaciones estructurales al subsistema que describe Habermas. Pero esto no ocurre sólo al examinar el ejemplo del trabajador, si tomamos el ejemplo del consumidor podemos encontrarlo como rol de corte más bien femenino. Y aún más, según esta categorización, si tomamos como ejemplo a las mujeres que viven solas con sus hijos vemos como ellas quedan excluidas casi por completo del mercado:

"[...] tanto como trabajadoras como consumidoras y son consideradas no como individuos sino como miembros de hogares incompletos. Todo esto significa que el desarrollo del rol del cliente en el capitalismo del bienestar tiene un sentido mucho más complejo que el que Habermas le da" (Oliva, 2009: 206).

Así critica también Fraser la noción de 'ambivalencia' del capitalismo del bienestar, y que bajo ella se escondería otra forma de subordinación de las mujeres.

Otros de los puntos principales de la crítica son, considerando la relación entre mundo de la vida y sistema, por un lado el hecho de que Habermas no parece tener en cuenta la posible influencia del mundo de la vida en el sistema, y es claro para Fraser que las normas y el significado de la identidad de género canalizan la influencia del mundo de la vida en el sistema; y, por otro lado, su insuficiente descripción de lo que supone la 'colonización del mundo de la vida'. Este último aspecto viene dado desde la perspectiva de la aparición de conflictos sociales, cuyo poder emancipatorio dependerá de hasta qué punto se posicionen como contrarios a la acción del sistema, y el problema aquí estaría, por tanto, en cómo evaluar y distinguir entre diferentes reivindicaciones. Ya que esto supondría sustituir los contextos de acción logrados normativamente (dados nomológicamente en el sistema) por otros que sean logrados comunicativamente (por medio del habla y la discusión en el mundo de la vida, dónde se impondría la peculiar coacción sin coacciones del mejor argumento en un estado ideal de habla). Así: 
“[...] la demanda habermasiana de 'descolonizar el mundo de la vida' deja de lado los problemas claves para el movimiento feminista. Por ejemplo, no trata la cuestión de cómo reestructurar la relación entre la crianza de los hijos, por una parte, y el trabajo asalariado y el ejercicio de la ciudadanía, por otra" (Oliva, 2009: 213).

Por otra parte, tenemos la crítica 'directa' a la idea de esfera pública habermasiana. Ésta se ha de entender como un espacio de debate, discursivo, donde una serie de actores, que se comportan estratégicamente, dialogando en una situación ideal de habla, con la intención de alcanzar un consenso, que se conseguirá mediante la ponderación de argumentos racionales y la imposición de la peculiar coacción sin coacciones del mejor argumento. Así, la acción comunicativa se entiende como el acto llevado a cabo por un actor que emite una serie de manifestaciones que remiten a pretensiones de validez que están racionalmente motivadas por razones y argumentos, y por ello son siempre criticables y corregibles.

Para Fraser la esfera pública en Habermas:

“[...] designa el foro de las sociedades modernas donde se lleva a cabo la participación política a través del habla. Es el espacio en que los ciudadanos deliberan sobre sus problemas comunes, por lo tanto, un espacio institucionalizado de interacción discursiva. Este espacio es conceptualmente distinto del Estado; es un lugar para la producción y circulación de discursos que, en principio, pueden ser críticos frente al Estado. [...] también es conceptualmente distinta de la economía oficial; no es un espacio para las relaciones de mercado. Por lo tanto, este concepto de la esfera pública nos permite mantener presentes las distinciones entre los aparatos de Estado, los mercados económicos y las asociaciones democráticas, distinciones esenciales para una teoría democrática" (Fraser, 1997:97).

Fraser admira precisamente la capacidad de la categorización habermasiana para distinguir con claridad, al menos en principio, entre los tres estratos. Uno de los problemas reside en como dilucidar que sea asunto privado y que público. Para Fraser no existe delimitación anterior de lo que sea público o privado, esto se dilucida de forma discursiva, mientras que Habermas contempla el espacio de la discusión como orientado al bien común, sin permitir, por tanto, que en él haya ningún tipo de intereses privados (esta misma crítica puede extenderse a la 'Öffentlichkeit' de Arendt). Así, para Fraser, se estaría limitando la posibilidad de la discusión pública, además de que es claro que este es uno de los puntos clave que obligan a Habermas a un cierto ideal de habla, ya que no se puede actuar igual en el marco discursivo que en otros ámbitos.

Y como defiende Fraser: "declarar el espacio de deliberación como un espacio en el que las distinciones existentes relativas a la posición social se ponen en suspenso y se neutralizan, no es suficiente para que esto suceda". (Fraser, 1997: 103) Ahora bien, según Fraser, la esfera pública tal y como la entiende Habermas: "permite eludir 
algunas de las confusiones que aquejan a los movimientos sociales progresistas y a las teorías políticas asociadas con ellos." (Fraser, 1997: 96) Así Fraser pone como ejemplo la incapacidad del socialismo y del marxismo para distinguir entre aparatos de Estado y los espacios públicos de discusión, así como, dentro del Feminismo, el caso de la mala utilización del término 'esfera pública'. Sin embargo: "la idea de 'esfera pública', en el sentido de Habermas, es un recurso conceptual que puede ayudarnos a superar estos problemas." (Fraser, 1997: 97) Pero Habermas se queda corto en su modelo, ya que este se reduce a un "modelo postburgués de esfera pública" (Fraser, 1997: 98).

Pero además añade que si de verdad todos estos supuestos se mantienen, por ejemplo el hecho de que se presuponga la supresión de las desigualdades sociales estructurales de los 'actores', esto es, un hacer como si no las tuvieran, ponerlas en suspenso en lugar de eliminarlas, entonces no podremos más que dudar acerca de la validez de una concepción tal. Concretando más, Fraser defiende un esquema del que se obtienen otras conclusiones, ya que a diferencia de Habermas:

"[...] fortalece la convicción de que hay que incorporar a la arena de la discusión política aspectos que tradicionalmente fueron excluidos del ámbito público y político circunscribiéndolos al privado y doméstico. $\mathrm{Y}$, sobre todo, torna comprensible la omisión de un papel explícito referido a la crianza de niños entre los papeles que vinculan a las esferas de cada orden" (Castillo, 2005: 84).

\subsection{FRENTE A ARENDT}

Volviendo a su disputa con Arendt, queda claro como Fraser no parece dispuesta a aceptar nada más ni nada menos de la teoría de Hannah Arendt que su capacidad de diagnóstico de la dinámica del desastre, y por ello pide que se traslade la estructura descrita por Arendt a nuestra sociedad actual en su obra Escalas de Justicia. Esto es, se admite la capacidad crítica de la teoría arendtiana, incluyendo su concepto de esfera pública, ya que, si tomamos como ejemplo su análisis del estalinismo, tenemos cómo: "En el estalinismo, por ejemplo, percibía ella un intento no muy distinto de remodelar la vida humana a gran escala; al buscar una visión única totalizadora, eliminaba también el espacio público y ponía en peligro la individualidad y la pluralidad." (Fraser, 2008: 235)

También para explicar el problema de la "transnacionalización de la esfera pública" Fraser se vale de un concepto muy parecido al arendtiano de esfera pública:

"El concepto de esfera pública no se desarrolló simplemente entender los flujos de la comunicación, sino más bien como contribución a una teoría crítica de la democracia. En esta teoría, una esfera pública se concibe como un espacio destinado a la formación comunicativa de la opinión pública" (Fraser, 2008: 146). 
Pero es necesario recordar la distancia que hay entre ambas concepciones, por ejemplo, en el hecho de que Fraser no comparte la distinción radical "a priori" entre público y privado. No queremos por ello decir aquí que no se perciba una cierta influencia arendtiana en su forma de esfera pública plural.

También es importante ver cómo concibe Arendt la 'esfera pública'. Como apunte preliminar debemos decir que, la 'Öffentlichkeit' y el 'Mitwelt' son un espacio libre en el que se pueda actuar. Para explicar este concepto, Hannah Arendt comienza por distinguir dos sentidos de la palabra público que, si bien están íntimamente ligados, no son idénticos. En primer lugar tenemos el aspecto más ligado a la publicidad, esto es, a lo que todos pueden ver y oír. En este sentido se opondría a la esfera de lo privado, de lo íntimo, de las pasiones. Y se propone una cierta predominancia de la esfera pública sobre la privada.

Además no podemos pasar por alto el hecho de que hay una idea de apropiado e inapropiado en la esfera pública (lo cual resuena inevitablemente a los modos de ser en Heidegger). Ya que hay muchas cosas que "no pueden soportar la intensa luz de la esfera pública" (Arendt, 2005: 72) y por ello son o pasan a ser asunto privado. A colación de este matiz podemos ver como Fraser explica que:

"En la medida en que el proceso es inclusivo e imparcial, se supone que el ámbito de lo público deslegitima puntos de vista que no resisten el examen crítico y certifica la legitimidad de los que sí lo hacen. Por ello, importa saber quién y participa y en qué términos lo hace. Además, una esfera pública se concibe como un medio de organizar la opinión pública como fuerza política. Movilizando el valioso sentido de sociedad civil, se supone que la publicidad hace que la autoridades públicas respondan ante ella y garantiza que las acciones del Estado expresen la voluntad de la ciudadanía" (Fraser, 2008: 146).

Aún así, esta concepción se alejaría claramente de la de Fraser, ya que si hay algo inadecuado se implica con ello la posibilidad de designar de antemano que sea público y que no. Para Arendt la cuestión de lo "inadecuado" posee un encanto tal que puede ser aceptado por un pueblo entero, de manera que asistiríamos a la reducción de la esfera pública. Este punto está aún más claro si cabe, ya que para Fraser se decide, discursivamente, lo que es público, de manera que no se puede decidir de antemano si algo es adecuado o inadecuado, y así su posición choca frontalmente con la de Arendt.

El segundo aspecto de lo público se entiende como mundo común, entendiéndose éste como lo común a todos y diferenciándose de nuestro lugar poseído privadamente en él. Aquí se plantea el conflicto de la sociedad de masas, y Arendt explica que lo que nos resulta tan imposible de soportar dentro de la sociedad de masas no es esencialmente la cantidad de personas sino más bien que el mundo ha perdido la 
capacidad de unirlas, separarlas, y relacionarlas. La sociedad de masas no sólo destruye la esfera pública, sino que también destruye la privada, ya que estas dos esferas sólo pueden existir mediante la mutua coexistencia. En este sentido sea tal vez en el que más se acerquen las dos pensadoras, ya que se toma mundo común como algo que se construye activa y políticamente. Se ve claramente que 'mundo común' viene a significar ese espacio que media, que está entre los hombres y es el que permite la interrelación. Arendt plantea aún un nuevo rasgo del mundo común, y es que en él todos ven y oyen algo desde diferentes perspectivas sin que por ello se varíe la identidad de es algo concreto. Como ya dijimos es aquí donde se aprecia un cierto punto común entre ambas posturas.

Es precisamente el hecho de que, a pesar de la variedad de perspectivas, todos estén interesados en un mismo objeto lo que garantiza principalmente la realidad, esto es, no es sólo mundo común en cuanto a compartido sino que lo es también en tanto que con un objeto, objetivo o dirección común. En el momento en el que deje de verse u oírse con claridad este objeto de interés común (en el momento en que no se reconozcan con claridad las reivindicaciones sociales o políticas y sus objetivos y campos de acción podría decir Fraser) es muy difícil evitar la destrucción del mundo común. Ya que los hombres se habrían convertido en totalmente privados, encerrados en la singularidad de su propia experiencia. Y esto puede implicar, asimismo, el fin de un mundo común ya que entonces sólo se ve bajo un aspecto y se le permite presentarse sólo desde una única perspectiva, lo que ocurriría, por ejemplo, y según el análisis arendtiano, bajo una dictadura.

En cuanto a las posibles objeciones de Fraser, el problema es, como ya hemos venido señalando, que:

"[...] a este respecto, no existen fronteras naturales dadas a priori. Lo que debe considerarse como un asunto de interés común será decidido, precisamente, a través de la confrontación discursiva. De lo anterior se sigue que ningún tópico debe ser excluido previamente a tal confrontación" (Fraser, 1997: 123).

A pesar de que esta apreciación es un ataque a la concepción habermasiana y no directamente dedicado a Arendt, es claro como sería aplicable a ambos enfoques, ya que en este punto, así como en la necesidad de excluir los intereses privados de la esfera pública, ambas posiciones son similares. En el caso de Habermas implicaría una mentira y una impostura que se descubriría racionalmente gracias a la falta de horizonte común, y en el caso de Arendt sería una forma de violencia, ya que no se respetaría la estructura de la acción ('Handlung'), se impondría un fin, por lo que se asimilaría a un trabajo, con horizonte delimitado. Ahora bien, en esta misma crítica de Fraser, es cierto que si continuamos leyendo con ella encontramos un nuevo punto común entre ambas, ya que Arendt no niega que se pueda cambiar el objeto último, ya que éste es algo siempre muy abstracto y que se ve desde múltiples perspectivas, por 
lo que éste no negaría las: "[...]garantías positivas para que las minorías puedan convencer a otros de que aquello que en el pasado no era público, en el sentido de de no ser de interés común, debería serlo ahora." (Fraser, 1997: 123) Pero esta reconciliación no es más que superficial, en cuanto avanzamos un poco más vuelve a insistir Fraser en el hecho de que:

“[...] la eliminación de las restricciones formales a la participación en la esfera pública no basta para asegurar la inclusión en la práctica. Por el contrario, incluso después de que las mujeres, las personas de color y los trabajadores han sido autorizados formalmente para participar, su participación puede ser obstaculizada por concepciones de la privacidad económica y doméstica que delimiten el alcance del debate" (Fraser, 1997: 127).

Una objeción más al concepto de esfera pública que describe Arendt vendría dado por el problema de las condiciones de inclusividad y paridad:

"[...] los teóricos de la esfera pública asumían implícitamente que la ciudadanía establecía los legítimos vínculos de inclusión, equiparando en la práctica a estos afectados con los miembros de una sociedad política delimitada. Tácitamente, también los teóricos apelaban a la ciudadanía para concretar la idea de paridad d participación en las deliberaciones públicas, asociando en la práctica la paridad en la comunicación con el estatus de igualdad política compartido en un Estado territorial" (Fraser, 2008: 176).

Tampoco podemos olvidar las numerosas críticas que ha recibido Arendt desde el feminismo, ya que la recuperación histórica y la división de actividades humanas que lleva a cabo Arendt resulta ciertamente falta de consideración de género, y esto no debe considerarse como un mero apunte, porque no se puede olvidar que estas actividades nunca han sido neutrales desde el punto de vista del género. Las principales cuestiones que se plantean como problemáticas serían: el hecho de que Arendt obvie la referencia de género y como caracteriza al 'animal laborans':

"[...] sujeción a la necesidad y a la carga de atender las necesidades de la vida, reducción a las necesidades corporales, y exclusión general de las actividades relacionadas con las funciones relacionadas con la esfera pública. A favor de Arendt podríamos argumentar que en su análisis no encontramos una asignación expresa a uno u otro sexo de cada una de las actividades. [...] Pero elude también cualquier mención a cuestiones tan relevantes como la división sexual del trabajo en el seno de la esfera privada" (Sánchez, 2006: 128-129).

Otro punto de la crítica sería el concepto arendtiano "reproducción", que está íntimamente relacionado con esta cuestión, ya que es al definir el concepto de labor cuando se muestra más claramente como Arendt asocia la reproducción con connotaciones negativas, en definitiva, el problema es que Arendt parece reproducir 
así el esquema tradicional que asocia a la mujer con la naturaleza y al hombre con la cultura.

Estas primeras críticas al pensamiento arendtiano desde el feminismo no implican que no se hayan recuperado determinados aspectos de la teoría de Arendt que puedan aportar nuevos enfoques. Hay más de una categoría relevante en el planteamiento de Arendt de alto potencial para el pensamiento feminista, tomemos aquí en consideración la natalidad y la pluralidad. Ambas categorías son centrales en la delimitación de la 'vita activa', ya que, por ejemplo, la natalidad pone en relación labor y acción. Lo que nos importa aquí es simplemente apuntar que estos conceptos siguen discutiéndose como problemáticos en el seno del feminismo filosófico. Además, la concepción activa de la política que predomina en Arendt coincide con muchas de las preocupaciones actuales del feminismo: participar en la construcción de un mundo común, ser vista y oídas, analizar el estado de 'paria', aparecer en público... Así lo que es importante es hacer ver cómo el pensamiento de Arendt posee una gran fuerza crítica que puede ayudarnos a avanzar, y que tampoco entraría en contradicción frontal, como podría parecer en un principio, con el planteamiento de Fraser.

\section{A MODO DE CONCLUSIÓN}

Con este artículo se pretendía exponer de forma clara parte del pensamiento de Fraser, pero además tratar de darle un cierto enfoque crítico a la exposición. Por ello me gustaría terminar por matizar algunos puntos polémicos. Es claro que el controvertido tríptico (redistribución-reconocimiento-representación) que forma Fraser puede resultar también problemático. Por ejemplo: no siempre responde definitivamente a cuestiones que parecen plantearse como puntos clave. Pero esto tiene también su punto positivo, Fraser no es una de esas autoras que parezca formar un sistema incorruptible, su fórmula resulta tan fuerte como flexible, en el sentido de que siempre se plantea una o varias alternativas con las que solventar el problema en cuestión. Resulta verdaderamente admirable la forma en que concilia una teoría crítica sólida con problemas empíricos. Así parece ofrecer siempre un camino, una vía a seguir, plenamente razonada y trabajada, pero siempre como invitación a seguir avanzando. No parece que pueda explicarse esto sólo por la dificultad de los temas que trata, sino que hay que tener también siempre en cuenta que su enfoque critica y fundamenta a la vez que expone. También podríamos considerarlo como un enfoque más conciliador, ya que sus críticas son siempre constructivas, de manera que al polemizar termina encontrando una especie de término medio.

La pretensión de Fraser pasa por abordar temas muy amplios así como complejos, quedando siempre su teoría como más abierta, como reconciliadora de varias posturas, en principio alejadas, por ejemplo, volviendo a mencionar el 
perspectivismo, y por ello puede llegar a ser complicado mantener su postura frente a algunas teorías reduccionistas que a nivel teórico puedan parecer mejor cerradas. Aquí es clara la referencia a la crítica de Honneth, quién no es capaz de ver las ventajas en el enfoque "perspectivista". Además, este carácter reconciliador se pone de manifiesto en la forma que tiene Fraser de acercarse a otros autores, ya que siempre reconoce una serie de aspectos favorables en una teoría determinada antes de pasar a criticarla.

Otro matiz sería distinguir la capacidad empírica, o adecuación a ejemplos concretos entre las dos obras citadas. En el caso de ¿Redistribución o reconocimiento? queda muy claro el ejercicio de adecuación con ejemplos concretos, el problema aparecería más bien en algunos tramos de Escalas de Justicia dónde parece perderse ligeramente este punto de vista empírico. A pesar de avanzar en el análisis al introducir la dimensión política que antes se tomaba como incluida en las otras dos, o quizás precisamente por eso, se pierde la referencia empírica ya que contamos con problemas más abstractos, tales como el des-enmarque. Mientras que en ¿Redistribución o reconocimiento? las reivindicaciones de redistribución y reconocimiento se consideraban directamente como políticas, de manera que no parecía necesaria una tercera dimensión que comprendiera la representación como ámbito diferenciado. Aunque este ejemplo tendría un correlato dentro de las actividades de los movimientos sociales, no es ya una reivindicación actual teorizada, sino más bien un concepto de la teoría de Fraser que puede encajar con una idea intrínseca a algunos movimientos sociales (activistas de la globalización).

Al respecto habría que señalar también la posible ambigüedad del término 'representación' ya que Fraser parece utilizarlo tanto en un plano simbólico como para referirse más directamente al sistema democrático. Esta cuestión es planteada también como pregunta en Escalas de justicia. Según Fraser utiliza precisamente el término 'representación' en parte por su polisemia, de manera que le permite diferenciar dos niveles. Por un lado podemos entenderlo como el orden o sentido directo de voz política; y por otro lado, como un metanivel en el que se pregunte por el marco. De aquí la diferencia entre representación fallida político-ordinaria y desenmarque. Pero aún así podríamos siempre preguntarnos en casos concretos sino sería más manejable un concepto menos laxo, que permitiera una mejor clasificación.

Pero por mucho que hagamos hincapié en su carácter reconciliador no podemos obviar que la teoría de Nancy Fraser es ciertamente arriesgada, el hecho de exigir, tanto los paradigmas de una teoría política democrática radical, como tratar de mantener el enfoque teórico crítico y un cierto socialismo clásico, combinado con un claro tinte pragmatista resulta ampliamente controvertido. Así podemos decir, junto con $\mathrm{M}^{\mathrm{a}}$ José Guerra, que: 
"Fraser pone toda la carne en el asador al servicio de la clarificación de las condiciones de posibilidad de una democracia verdaderamente radical. De un lado, el logro de la igualdad de oportunidades para todos mediante una efectiva redistribución de los recursos socioeconómicos, del otro la garantía de la infraestructura moral y simbólica del reconocimiento. [...] El reto vuelve a ser "entretejer", una y otra vez, la teoría y la práctica" (Guerra: 2006, 165).

Tendríamos que añadir, tal vez, el carácter político de las reivindicaciones como desarrolla en Escalas de Justicia, y su incesante objetivo de oponerse a la desigualdad, pero me parece claro como la propuesta de Fraser queda así caracterizada como un proyecto de gran envergadura y capacidad crítica.

Por todo lo dicho, es claro que Nancy Fraser defiende un modelo siempre multidimensional y polémico, que, a pesar del cambio sufrido entre las dos obras principalmente estudiadas, esto es, la adición de un tercer aspecto la 'representación', presenta su teoría como una postura claramente solvente, formada por la relación triple, nunca entendida como subordinación de reconocimiento, redistribución y representación, representando así los tres ámbitos sociales: cultura, economía y política. Y comprendidas estas como elementos fundamentales de la justicia, reconciliando así los tres ámbitos.

\section{BIBLIOGRAFÍA}

ARENDT, HANNAH (2005) La condición humana, Paidós, Barcelona.

BENHABIB, SEYLA; BUTLER, JUDITH; CORNELL, DRUCILLA; FRASER, NANCY (1995) Feminist contentions. A philosophical Exchange, New York, Thinking Gender by Routledge.

CASTILLO, RAMÓN DEL (2005) El feminismo de Nancy Fraser: Crítica cultural y de género en el capitalismo tardio en Amorós Puente, Celia y de Miguel, Ana (eds.) Teoría Feminista: de la Ilustración a la globalización, vol. II, Págs. 61-120, Madrid, Biblioteca Nueva.

FRASER, NANCY (2008) Escalas de Justicia, Barcelona, Herder.

FRASER, NANCY y HONNETH, AXEL (2006) ¿Redistribución o reconocimiento?, Madrid, Morata.

FRASER, NANCY (1989) Unruly Practices. Power, Discourse and Gender in Contemporary Social Theories, Cambridge, Polity Press.

FRASER, NANCY (1997) Iustitia Interrupta: Reflexiones críticas desde la posición postsocialista, Santafé de Bogotá, Siglo del hombre Ediciones, Universidad de los Andes.

FRASER, NANCY (1990) ¿Qué tiene de crítica la teoría crítica? Habermas y la cuestión del género, en: Benhabib, Seyla \& Cronell, Drucilla (eds.) Teoría 
feminista y teoría crítica. Traducción de Ana Sánchez, Valencia, Ed. Alfons el Magnánim.

FRASER, NANCY (2009) El feminismo, el capitalismo y la astucia de la historia, en New Left Review n ${ }^{\circ}$ 56, Mayo/Junio.

GUERRA, MARÍA JOSÉ Nancy Fraser en Guerra, Ma José y Hardisson, Ana (eds.) (2006) Pensadoras del siglo XX, Tomo II, Págs. 147-168, Ediciones Nobel, Oviedo.

HABERMAS, JÜRGEN (2003) Teoría de la acción comunicativa, 2 Vols. Taurus, Madrid.

OLIVA, ASUNCIÓN (2009) La pregunta por el sujeto en la teoría feminista. El debate filosófico actual, Editorial Complutense, Madrid.

SÁNCHEZ, CRISTINA Hannah Arendt en Guerra, Ma José y Hardisson, Ana (eds.) (2006) Pensadoras del siglo XX, Tomo I, Págs. 125-146, Ediciones Nobel, Oviedo. 